\title{
A98-25287
}

AIAA-98-2108

\section{BENCH-TOP CHARACTERIZATION OF AN ACTIVE ROTOR BLADE FLAP SYSTEM INCORPORATING C-BLOCK ACTUATORS}

\author{
Joseph W Clement*, Diann Brei ${ }^{\dagger}$, and Andrew J. Moskalik ${ }^{\ddagger}$ \\ The University of Michigan \\ Ann Arbor, Michigan 48109-2125 \\ Ron Barrett ${ }^{\S}$ \\ Auburn University \\ Auburn University, AL 36849-5338
}

\begin{abstract}
This paper presents the bench-top testing of a piezoceramic C-block driven active flap system designed to suppress the vibrations of a helicopter rotor blade. The C-block actuators are curved benders designed to generate a larger force output than a straight bender, while providing deflections large enough to eliminate the need for external leveraging systems necessary with stack driven systems. The actuators power a balanced active flap designed to minimize the effect of air speed and rotor speed on flap deflection. Quasi-static experimentation at $1 \mathrm{~Hz}$ produced maximum angular flap deflections of $8.4^{\circ}$ peak-to-peak. Dynamic tests were conducted over a $40 \mathrm{~Hz}$ frequency range demonstrating the ability to generate significant flap deflections both before and after the first natural frequency. Over the $40 \mathrm{~Hz}$ range, the flap deflections never dropped below $8^{\circ} \mathrm{pp}$, with a first natural frequency of $27 \mathrm{~Hz}$. The flap deflection reached a maximum value of $13.6^{\circ} \mathrm{pp}$ at $40 \mathrm{~Hz}$. If the applied voltage is increased to the maximum allowable level, it is predicted that flap deflections as large as $20^{\circ} \mathrm{pp}$ can be achieved.
\end{abstract}

\section{Introduction}

One of the main problems affecting modern helicopter performance is the large vibratory loads generated as the rotors travel through an extremely complex flow

\footnotetext{
*Graduate Student, Department of Mechanical Engineering and Applied Mechanics

${ }^{\dagger}$ Assistant Professor, Department of Mechanical Engineering and Applied Mechanics

${ }^{\ddagger}$ Ph.D. Candidate, Department of Mechanical

Engineering and Applied Mechanics

${ }^{\S}$ Assistant Professor, Department of Aerospace Engineering

Copyright $\odot 1998$ The American Institute of Aeronautics and Astronautics Inc. All rights reserved.
}

field. The primary source of the vibrations is the differential in air speeds encountered by the retreating and advancing blades. Because the air speed is much lower over the retreating blade, an increase in the retreating blade's pitch is required to maintain lateral stability. As a result of the pitching action, a N/rev load is transmitted to the fuselage for a $\mathrm{N}$-bladed balance helicopter. In addition to the physical discomfort experienced by the passengers, the vibrations create excessive levels of noise. This noise limits the use of helicopters in domestic affairs as well as military efforts. In addition, these vibrations cause premature replacement of the rotor blades, with typical rotor blade sets pricing in the five to six figure range. Currently, helicopters control the blade pitch through the use of a swashplate, driven by actuators in the non-rotating system. The difficulty of transferring mechanical power from the non-rotating to the rotating system has limited the usage of Higher Harmonic Control (HHC) or Individual Blade Control (IBC) in today's helicopters, causing a reliance on passive methods to reduce vibrations.

However, the limited bandwidth of passive vibration control has stimulated much research in active vibration suppression methods that would overcome the difficulty of power transfer to the rotor system. Researchers have investigated placing actuators in the rotating frame, eliminating the heavy, complex mechanisms necessary to transform control efforts from the fixed to the rotating system, thereby increasing the effectiveness of both HHC and IBC. A number of different actuation systems utilizing smart materials have been examined for this purpose, including hybrid systems where smart materials are combined with hydraulics ${ }^{1,2,3}$. The most widely used smart material is piezoelectrics. Conventional piezoelectric actuators, such as stacks ${ }^{4,5}$ and bimorphs $s^{6,7,8}$, have been constructed to actuate smart flaps with promising results. However, the primary problems facing many of the current designs for active flap control have been the authority of the 
actuator and the sensitivity of the flap deflection to rotor speed and the frequency of flap excitation. To avoid these problems, a new approach to active flap actuation was implemented, C-blocks. These actuators can be combined in series and parallel to tailor the actuator's performance to the required force, deflection and bandwidth while fitting within the constrained blade space. This paper describes a balanced active rotor blade flap system incorporating this new actuation scheme. Presented is the design of an active rotor blade flap test article along with the fabrication and characterization of the actuation system, both independently and integrated into the flap test system.

\section{Active Rotor Blade Flap Test Article Desion} An active rotor blade flap test article driven by C-block actuators was designed for wind tunnel testing scheduled in the future. The design focused on three areas: active rotor blade section, C-block actuators, and the integrated test article.

\section{Active Rotor Blade Section Design}

Previous efforts to implement $\mathrm{HHC}$ and IBC rotor blade flap systems have incorporated unbalanced flaps. Because they are not balanced, the flap deflections of these systems are considerably degraded at nominal speeds by aerodynamic and inertial moments, and are highly sensitive to gust loads. In addition, they have the potential danger of aerodynamic control surface lock. The C-block based active rotor blade flaps are both aerodynamically and mass balanced, and thus should reduce, if not eliminate, many of these problems which have plagued earlier active flaps. The rotor blade section used in the wind tunnel test specimen is a 12 inch chord carbon fiber model of a NACA 0012 fully symmetrical rotor blade incorporating a carbon fiber flap mounted with twin precision bearings. The flap was designed to be both mass and aerodynamically balanced by co-locating the center of gravity, the center of pressure, and the hinge axis (Figure 1). This advancement over previous designs provides several key advantages. The mass balancing reduces the inertial load of the flap. Previous efforts by other investigators have not incorporated mass balancing, thereby requiring the actuator translate the flap's center of gravity. Since acceleration is proportional to time $e^{-2}$, the force required to translate the flap's mass, will increase with the square of the frequency of flap oscillation. Consequently, a given actuator can produce large flap deflections over a wider frequency range when driving a mass balanced flap as opposed to an unbalanced flap.

The aerodynamic balancing is the most important aspect of the flap design. The location of center of pressure at the hinge axis nearly eliminates the moment generated by aerodynamic loads on the deflected flap. The aerodynamic loads on the balanced flap act both fore and aft of the hinge axis. As the flap is deflected, the center of pressure will shift slightly, but over the limited angular deflection range, $<20^{\circ}$ peak-to-peak, of the flap, the center of pressure remains approximately on the hinge axis. Because the oncoming airflow does not introduce a significant moment on the flap, the flap

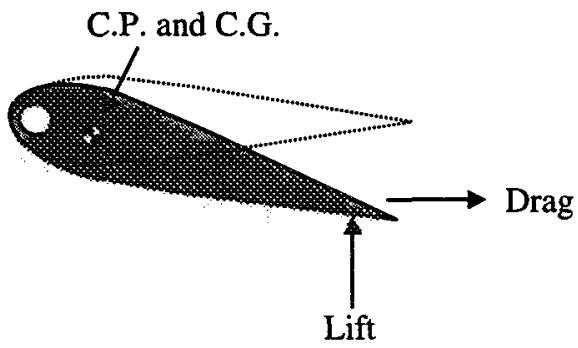

Aerodynamic moment $\gg$ zero

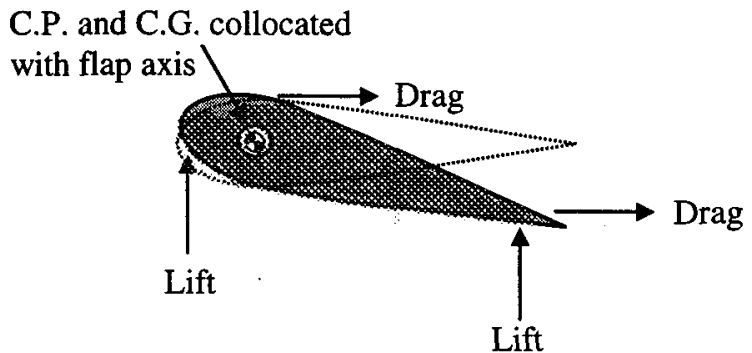

Aerodynamic moment $\approx$ zero

\author{
Conventional Flap \\ Large aerodynamic hinge moment \\ Large inertial load \\ High sensitivity to rotor speed \\ Risk of control surface lock
}

\author{
Balanced Flap \\ Low aerodynamic hinge moment \\ Low inertial load \\ Reduced sensitivity to rotor speed \\ Eliminates risk of control surface lock
}

Figure 1 : Conventional vs. Balanced Flap: Previous efforts to create an active rotor blade flap system have incorporated non-balanced conventional flaps. As a result, the conventional flap systems have been highly sensitive to the rotor speed. The improved balanced flap is designed to reduce if not eliminate this sensitivity. 


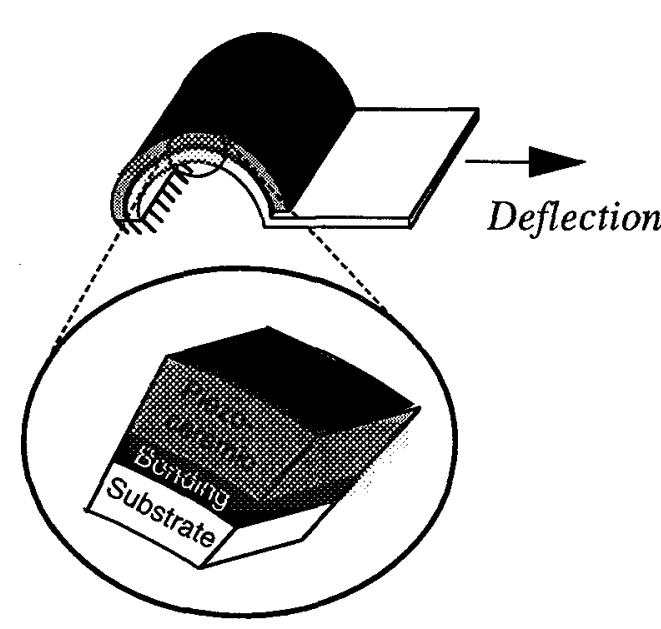

a) Individual C-block Element

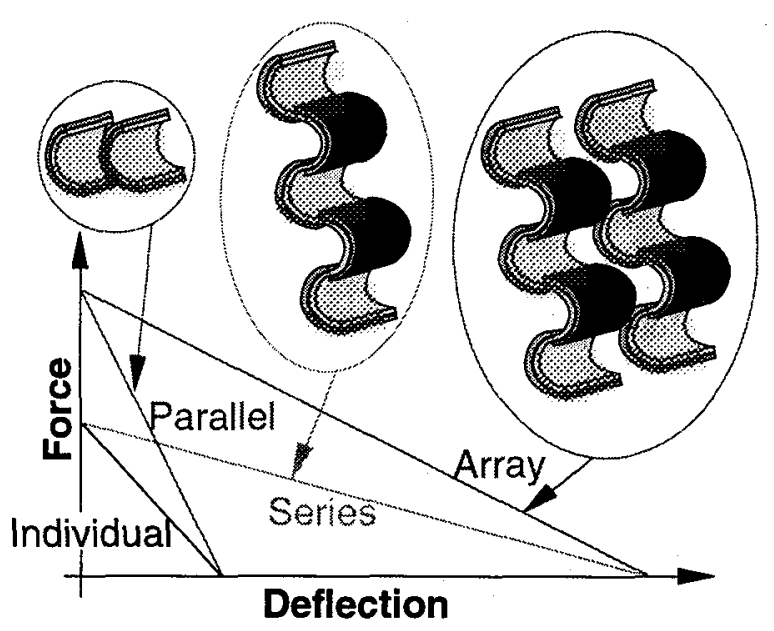

b) Different C-block Architectures

Figure 2: Internally Leveraged C-block Actuator: a) The curved shaped of the C-block creates a actuator capable of delivering $8 \%$ more work than a straight bender. A unimorph design allows for only compressive forces in the piezoceramic layer of the C-block, diverting the tensile loads to more durable steel substrate. b) The C-block architecture lends itself well to both serial and parallel combination to increase deflection and/or force output.

deflection will be less sensitive to the air speed over the rotor blade. This characteristic of the aerodynamically balanced flap is in strong contrast to a conventional flap, where the aerodynamic loads at high speed can surpass the actuators maximum force output, thereby preventing flap deflection.

\section{C-block Actuator Design}

Even though the requirements of the actuator are reduced by the new blade design, they are still challenging for the current actuation technologies. Therefore a new approach to actuation was chosen, $\mathrm{C}$ blocks (Figure 2a). The C-block acts much like a straight piezoelectric bender in that it is internally leveraged. A voltage field applied across the radial direction of the C-block causes an induced piezoelectric moment in the C-block. This moment generates an extension or contraction of the C-block creating a deflection at the tip. The curved shape increases the stiffness of the actuator, allowing it to produce 2.666 times the force, with 0.405 times the deflection of a comparable straight bender ${ }^{9}$. As a result, the C-block is capable of $8 \%$ more work output than a straight bender. However, the real strength of the C-block is its ability to be combined into an array structure of series and parallel members (Figure 2b). The addition of C-blocks in series provides a linear increase in the deflection of the actuator without a loss in output force, whereas the output force increases linearly with the addition of $\mathrm{C}$ blocks in parallel, without a loss in deflection ${ }^{10}$.
Having these extra design freedoms from the actuation architecture aids considerably in meeting application requirements within constrained volumes without having to resort to external leveraging.

\section{Integrated Test Article Desion}

For the active rotor blade flap, there are many different actuation configurations that can meet the requirements. The system chosen consists of two C-block actuators each comprised of eight $10 \mathrm{~mm}$ outside radius C-blocks (Figure 3) in series. The two C-block actuators are configured in parallel and operated in a pull-pull manner to drive the trailing edge flap, as shown in Figure 4. The two actuators are electrically connected in series, such that a single input voltage produces the necessary out of phase motion between the two actuators. The flap is actuated by directly attaching the actuation system to the flap rod, which acts as the hinge axis of the flap. The sine of the angular flap deflection is given by the ratio of the actuator deflection to the radius of the flap rod. With a $1 / 8$ inch diameter flap rod, the goal of $10^{\circ} \mathrm{pp}$ of flap deflection requires an actuator deflection of $\pm 138 \mu \mathrm{m}$.

\section{Prototype Fabrication}

A prototype of the active rotor blade flap test article was fabricated in three stages: Active rotor blade section, C-block actuator fabrication, and integration of test article. Each stage is described below. 


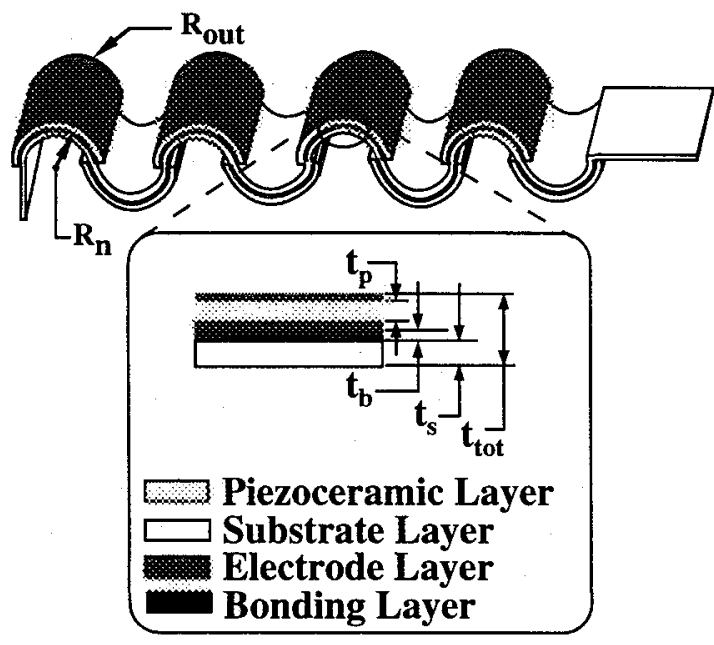

\begin{tabular}{|lcc|}
\hline & $\begin{array}{c}\text { Actuator 1 } \\
(\mathrm{mm})\end{array}$ & $\begin{array}{c}\text { Actuator 2 } \\
(\mathrm{mm})\end{array}$ \\
Outer radius, $\mathrm{R}_{\text {out }}$ & 9.99 & 9.99 \\
Neutral Axis radius, $\mathrm{R}_{\mathrm{n}}$ & 9.033 & 9.078 \\
Piezoceramic thickness, $\mathrm{t}_{\mathrm{p}}$ & 0.838 & 0.838 \\
Substrate thickness, $\mathrm{t}_{\mathrm{s}}$ & 0.455 & 0.455 \\
Bonding layer thickness, $\mathrm{t}_{\mathrm{b}}$ & 0.187 & 0.120 \\
Total thickness, $\mathrm{t}_{\mathrm{tot}}$ & 1.48 & 1.41 \\
\hline
\end{tabular}

Figure 3: Serial C-block Actuator: The actuators designed for the wind tunnel test specimen are comprised of eight C-blocks combined in series. The measured dimensions for the two actuators are given in the table.

\section{Rotor Blade Section Fabrication}

The rotor blade shell was fabricated in three major stages. The first was to construct a male mandrel for the 12 inch $(35 \mathrm{~cm})$ chord NACA 0012 blade section from high temperature polyester casting resin and held to $0.1 \%$ dimensional tolerances. The second stage of fabrication was to lay-up and pull the composite skins from the mandrels. Thornel ${ }^{\mathrm{TM}}$ P75-s graphite-epoxy cloth was laid up on the mandrels and cured at $250^{\circ} \mathrm{F}$ $\left(121^{\circ} \mathrm{C}\right)$ for 2.5 hours under 12.6 psi of pressure. The final stage of fabrication involved deflashing and assembly. The components were held to $0.1 \%$ dimensional tolerances and joined with cyanoacrylate resin. The $10 \%$ chord flap was given a $50 \%$ overhang to balance aerodynamic moments and pivoted around a pair of 0.125 inch $(3.18 \mathrm{~mm})$ diameter precision bearings. The completed rotor lade section is pictured in Figure 5.

\section{C-block Actuator Fabrication}

The C-blocks were fabricated from $10 \mathrm{~mm}$ outside radius PZT-5H half-tubes, of $0.84 \mathrm{~mm}$ thickness, as purchased from Morgan Matroc Electro Ceramics Division. The C-block actuators were fabricated using a three-step process. First, a mild carbon steel strip was formed into an S-shape (Figure 6a), conforming to the inner diameter of the semi-circular piezoceramic tubes, forming the backbone of the serial C-block actuator. Second, the piezoceramic half-tubes were epoxied to the steel substrate with an Insulcast 501 epoxy manufactured by Permagile Industries. After the epoxy had cured, seven small wires were soldered to each set of adjacent piezoceramics, thereby linking them electrically in series. Finally, an eighth wire was soldered to the first piezoceramic C-block, providing a power lead for the actuator. The completed actuator is

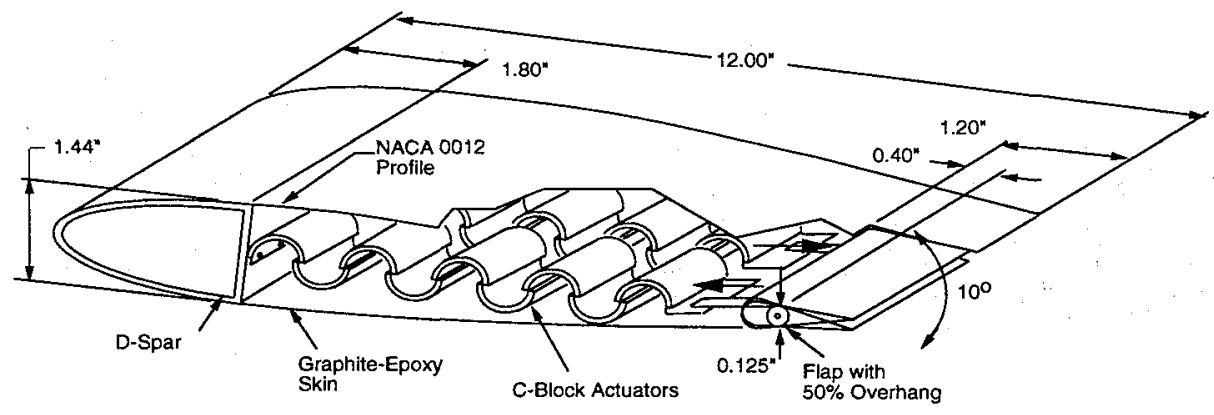

Figure 4: Active Flap System Design: The schematic gives the system design for the active rotor blade flap test article along with dimensions for the rotor blade section. Two C-block actuators drive a balanced active rotor blade flap to suppress the vibrations of a helicopter rotor blade. 


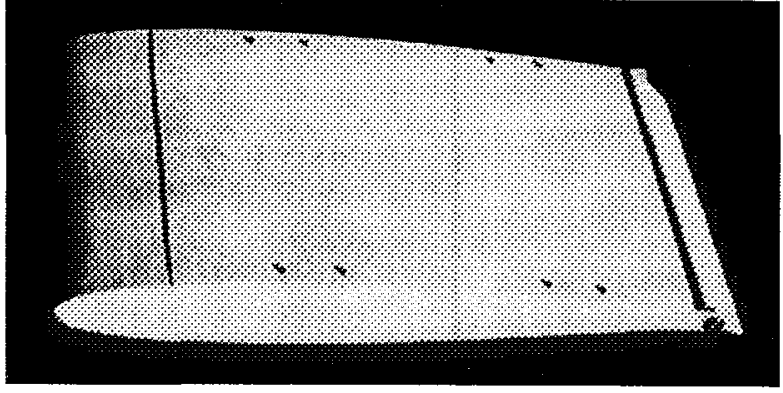

Figure 5: Assembled Rotor Blade Section: The carbon fiber rotor blade section and flap are fabricated to $0.1 \%$ dimensional tolerances.

shown in Figure 6b. Two actuators were fabricated using this method. These two actuators were identical except for the thickness of the epoxy layer, which varied by approximately $40 \%$, with a $0.187 \mathrm{~mm}$ thickness on actuator 1 and a $0.120 \mathrm{~mm}$ thickness on actuator 2 .

\section{Integration of the Test Article}

The characterized actuators were fitted into the rotor blade to experimentally test the performance of the integrated blade-actuator system. Cap screws were slid through the blade section's aluminum spar and tightened with nuts. The actuators were slid onto the cap screws and held in place with two lock nuts per actuator (Figure 7).

A $1 / 2$ inch by $1 / 4$ inch by approximately $71 / 2$ inch hollow brass rectangular bar was riveted to the opposite end of the actuators to provide an anchor for the brass shim stock used to transfer the deflection of the actuators to the flap rod. Hollow stock was used to keep the bar's weight from significantly affecting the dynamic performance, while the rectangular cross section

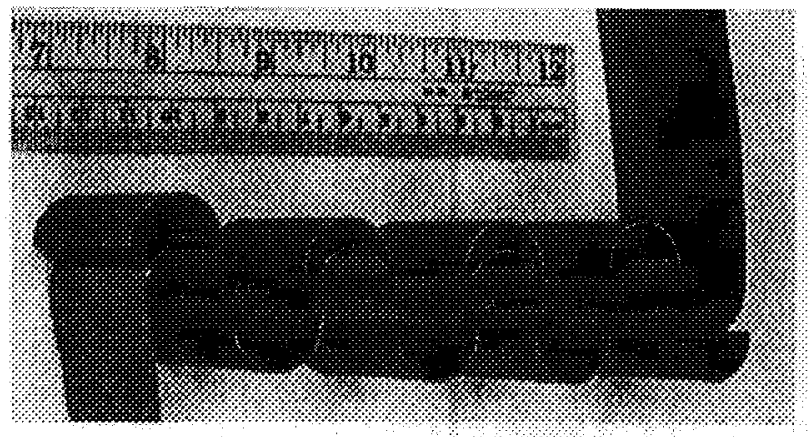

a) Unassembled Serial C-block Actuator provided the required rigidity. Riveting allowed the connection be very tight so that no deflection is lost due to play between the actuators and the rectangular bar stock.

Two $1 / 2$ inch wide, 1 mil thick, pieces of brass shim stock were affixed to the rectangular stock by wrapping the shim stock around the rectangular stock and applying super glue. Brass was chosen for the shim stock because of its flexibility, which was needed to round the $1 / 8$ inch diameter flap rod without kinking. The longitudinal stiffness of the shim stock was determined to be greater than an order of magnitude stiffer than the actuator, preventing loss of flap motion due to elongation of the shim stock. The shim stock was fed through a slot cut into the hollow flap and wrapped around the flap rod. The free end of the two pieces of shim stock were then attached to the second actuator in an identical manner, resulting with each shim stock forming a U-shape around the flap hinge allowing a pull-pull operation of the actuators to drive the flap.

\section{C-block Actuation System Experimental Characterization}

A series of experiments were conducted to determine the performance characteristics of the C-block actuators independent of the rotor blade section. The primary parameters of concern are the output force, displacement, and bandwidth of the actuator. The static force and deflection outputs of the C-block actuators in response to an applied DC voltage provide characterization of the actuators' maximum output. A dynamic analysis was performed to determine the natural frequencies of the actuators and the frequency range at which the actuators can provide large enough deflections for rotor blade vibration control. The actuator testing provided a base line to which the results

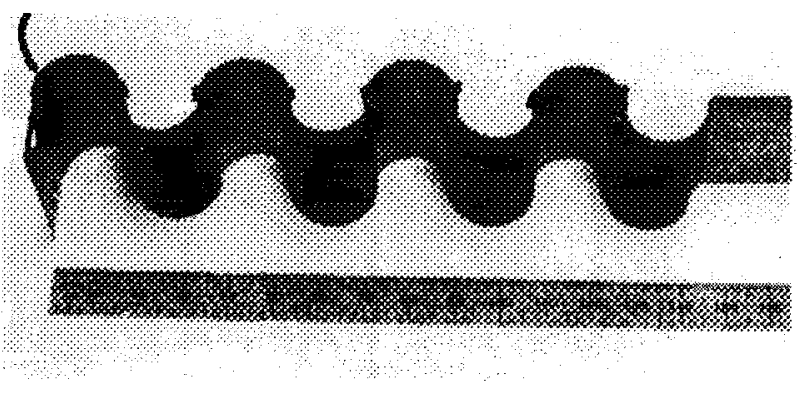

b) Complete Serial C-block

Figure 6: Serial C-block Actuator Prototype: a) Eight piezoceramic half-tubes were epoxied to a steel substrate which has been formed into an S-shape. b) Each half-tube as electrically wired in series to complete the actuator prototype. 


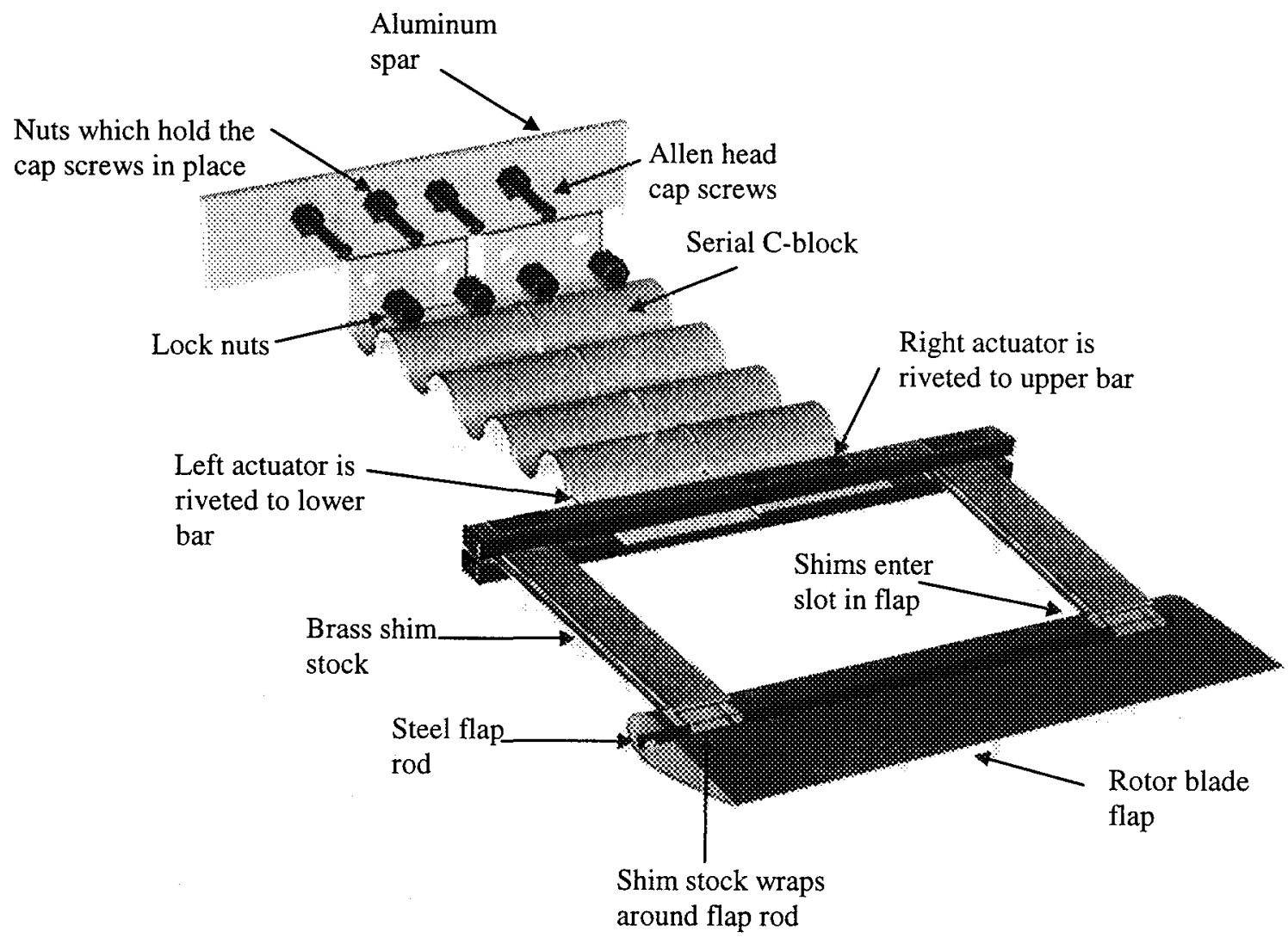

Figure 7: Integration of Actuators with Blade Section: Two C-block serial actuators were fixed to the spar of the wind tunnel test specimen with two lock nuts each. The actuators were attached to the flap by inserting two pieces of brass shims through the slot located on the leading edge of the flap and wrapping it around the flap rod.

from the testing of the integrated blade-actuator system were compared. The applied voltages used in the tests on the C-block actuators alone were limited to $150 \mathrm{~V}$, although the piezoceramics are specified with a maximum allowable voltage of $340 \mathrm{~V}$. The voltage was limited to prevent the possibility of damaging the actuators prior to future wind tunnel testing.

\section{Experimental Apparatus}

The C-block actuators were tested with the experimental setup shown in Figure 8. All tests were conducted with the actuators securely clamped in a vise to prevent erroneous results. For static experiments, DC signals were applied to the actuators with an Oregon Electronics Model D4 DC voltage supply. For quasi-static and dynamic experiments, sinusoidal waveforms were produced by an HP 33120A function generator, with amplification performed by a Trek 50/750 amplifier connected directly to the C-block actuator. Tip deflection measurements were taken with a Philtec A88NE1 fiber optic displacement sensor and read with a Fluke multimeter. Tip force measurements were taken with a Cooper Instruments LPM620 force transducer.

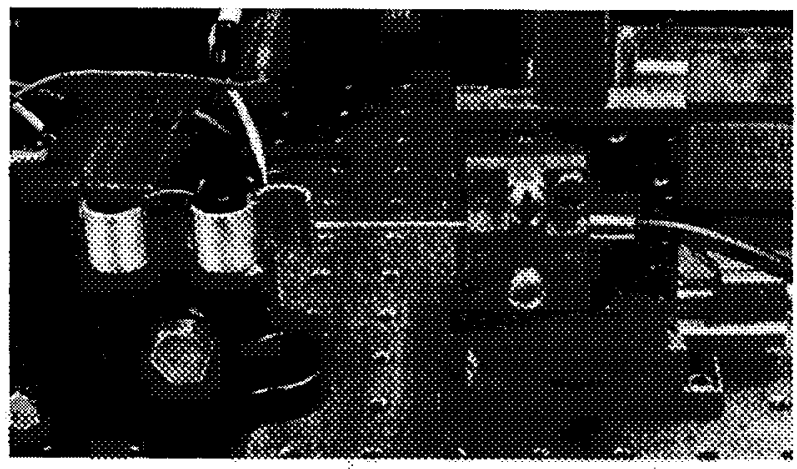

Figure 8: Actuator Testing Experimental Setup: Displacement measurements were taken with a Philtec Fiber optic probe. Force measurements were taken with a Cooper Instruments force transducer. 
Deflection-Voltage Experiments

The first experimental test performed on the actuators was the deflection-voltage test. The deflection-voltage model for a serial C-block actuator has been derived by Moskalik and $\mathrm{Brei}^{11}$ as:

$$
\Delta=\frac{2 n M^{P} R_{n}^{2}}{D}
$$

where $\mathrm{n}$ is the number of C-blocks in series, $R_{n}$ is the location of the neutral axis, $M^{P}$ is the internal piezoelectric moment, and $D$ is the composite bending stiffness of the C-block.

The location of the neutral axis is defined as:

$$
R_{n}=\frac{\sum_{i=1}^{3} \frac{1}{2} Y_{i} b_{i}\left(r_{i}^{2}-r_{i-1}^{2}\right)}{\sum_{i=1}^{3} Y_{i} b_{i}\left(r_{i}-r_{i-1}\right)}
$$

where the subscript $i$ denotes each layer of the C-block, $Y$ is the Young's modulus, $b$ is the width, and $r$ is the outer radius of each layer. The inner radius of the $\mathrm{C}$ block is denoted by $r_{0}$.

Both the piezoelectric moment and the composite bending stiffness are calculated using the distance of the outer edge of each $i$ layer, $z$, from the neutral axis. The piezoelectric moment, $M^{P}$, and composite bending stiffness, $D$, are defined as:

$$
\begin{aligned}
M^{P} & =\sum_{i=1}^{3} \frac{1}{2} Y_{i} b_{i}\left(d_{31} V\right)\left(z_{i}-z_{i-1}\right) \\
D & =\sum_{i=1}^{3} \frac{1}{3} Y_{i} b_{i}\left(z_{i}^{3}-z_{i-1}^{3}\right)
\end{aligned}
$$

where $V$ is the applied electric field applied across the piezoelectric material and $d_{31}$ is the piezoelectric constant.

To confirm that the actuators perform as predicted by the model, the deflection response of the actuators was measured for DC input signals. The voltage was increased from 0 VDC to 150 VDC and back to 0 VDC in increments of $10 \mathrm{~V}$. The deflection of the actuators was recorded at each step using the fiber optic probe.

The results of the deflection-voltage experiments for both actuators are depicted in Figure 9. Both actuators

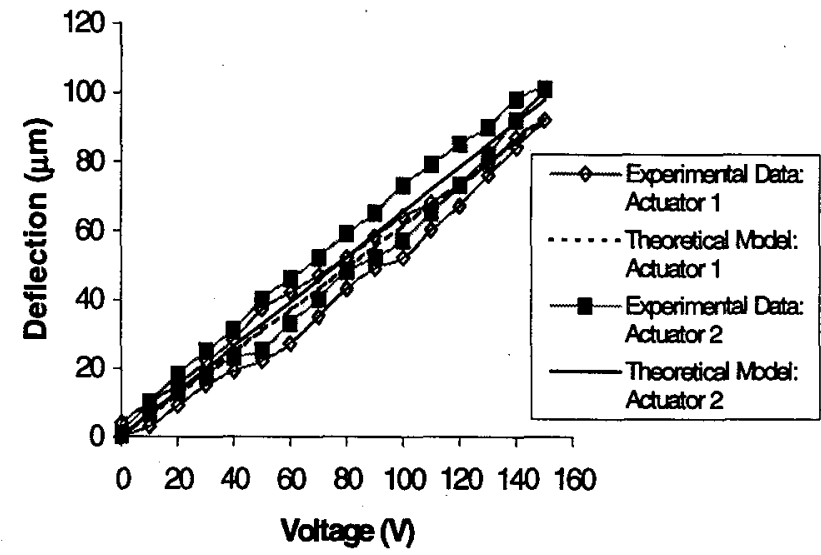

Figure 9: C-block Actuator Deflection-Voltage Relationship: The experimental and theoretical deflection response of both actuator 1 and actuator 2 plotted against the applied voltage to each actuator.

follow their respective theoretical relationship very well. Two separate theoretical lines are necessary because the approximately $40 \%$ difference in the bonding layer thickness significantly alters the bending stiffness, $\mathrm{D}$, and thus the predicted deflection. Actuator 1 produced a maximum deflection of $92 \mu \mathrm{m}$ with an average error of $4.8 \%$ of the total deflection. Actuator 2 produced a maximum deflection of $101 \mu \mathrm{m}$, approximately $3.2 \%$ higher than predicted by the theoretical model, corresponding to a $9.8 \%$ increase in deflection over actuator 1 . The average error in the deflection-voltage response of actuator 2 was $4.9 \%$. For both actuators, hysteresis, which was not accounted for in the theoretical model, is observed as the primary source of error. Hysteresis tests demonstrated maximum variations in deflection of $10.2 \%$ of the total deflection for actuator 1 and $13.4 \%$ of the total deflection for actuator 2 . The average of the maximum deflections achieved by both C-block actuators was 97 $\mu \mathrm{m}$, lower than the goal of $138 \mu \mathrm{m}$. However the voltage during the deflection-voltage test was limited to $150 \mathrm{~V}$, less than $45 \%$ of the maximum allowable voltage. If the maximum allowable voltage of $340 \mathrm{~V}$ is used then the deflection would be $220 \mu \mathrm{m}$ which is well above the requirement.

\section{Force-Deflection Experiments}

The second experimental test conducted was the forcedeflection test. The analytical model describing the force-deflection relationship of a series configured Cblock actuator is presented in detail by Moskalik and $\mathrm{Brei}^{12}$ and is summarized in equation 5 . 


$$
F=-\frac{2 D}{n \pi R_{n}^{3}} \Delta+\frac{4 M^{P}}{\pi R_{n}}
$$

Equation 5 is reduced to equation 1 when the force applied to the actuator, $F$, is set to zero, thereby predicting the free deflection of the actuator. The maximum blocking force is determined by forcing the tip deflection of the actuator, $\Delta$, to be zero.

To confirm that the actuators perform as predicted by the force-deflection model, a Cooper. Instruments force transducer was mounted on a Newport precision calibrated stage that allowed the transducer to move in the actuators longitudinal direction. The initial position of the actuator tip was recorded using the stage prior to the application of voltage. Voltages of 50,100 , and 150 VDC were applied to the actuators. After the voltage was applied, the stage was used to back the transducer away from the actuator to find the free deflection of the actuator. The stage was then incremented in $5 \mu \mathrm{m}$ steps back to the zero deflection point and the force and deflection of the actuator tip was recorded at each step.

The results of the force-deflection experiments are depicted in Figure 10. Maximum blocking forces of $10.1 \mathrm{~N}$ for actuator 1 and $9.2 \mathrm{~N}$ for actuator 2 were obtained for the 150 VDC input signal. Each actuator's experimental results demonstrated an average error of $2.6 \%$ from their respective theoretical models. The

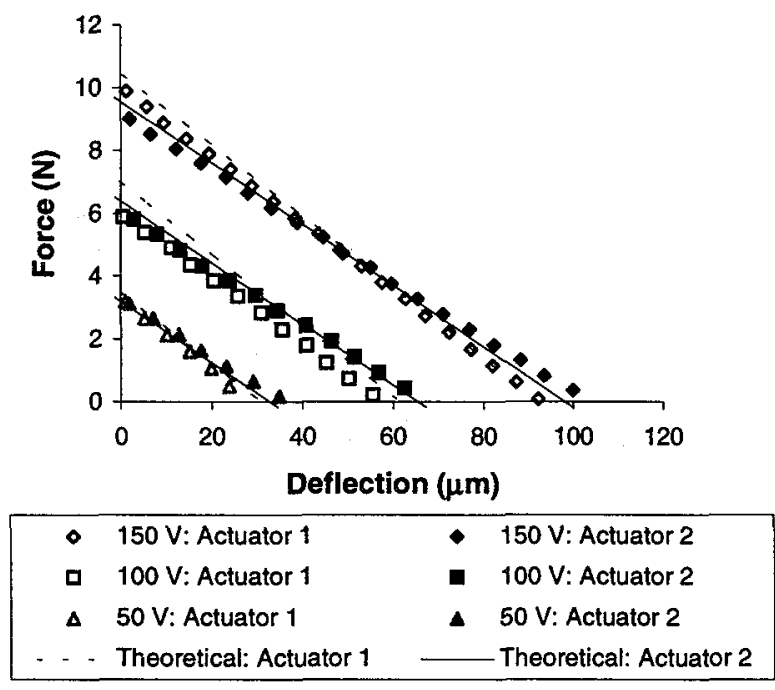

Figure 10: C-block Actuator Force-Deflection Relationship: The experimental and theoretical output force of both actuator 1 and 2 plotted against deflection in response to applied voltages of $50 \mathrm{~V}, 100 \mathrm{~V}$, and 150 $\mathrm{V}$.
9.8\% difference between the blocking force of the two actuators is attributable to the variation in the bonding layer thickness between the two actuators which significantly effects the bending stiffness. The percentage difference in the blocking force of each actuator is nearly identical to the percentage difference in the deflection of each actuator found during the deflection-voltage test, demonstrating the repeatability of the experimental tests. The stiffness of each actuator was slightly different from that predicted by the model. The experimentally determined stiffness of actuator 1 and actuator 2 were determined to be $5.6 \%$ and $8.9 \%$ lower than their respective models predicted. Actuator 2 exhibited an approximately $3.3 \%$ higher error in the stiffness which was also observed in the deflectionvoltage tests, where actuator 1 produced a $3.2 \%$ larger deflection than predicted by theory. This observation provides insight to the source of the error in both the deflection-voltage and force deflection-response. As seen in equations 1 and 5 , both the force and deflection output of the actuator is linearly dependent on the bending stiffness, $D$, of the actuators. Therefore a constant percentage error in the calculation of the bending stiffness of the actuator, results in a constant percentage error in both the force, and deflection measurements. As stated earlier, this error is due to the uncertainty in the thickness of the boundary layer. However, the small percentage errors in the results, despite the fabrication inaccuracies, indicate that the models are quite good, and the actuators perform as designed.

\section{Dynamic Performance Experiments}

The dynamic performance of the actuators was experimentally found to determine the actuators natural frequencies and if the actuators were capable of providing large deflections over a substantial frequency range. This will be necessary, if multiple vibratory loads are to be reduced. To characterize the dynamic performance, a $10 \mathrm{~V}$ amplitude sinusoidal signal was applied to the actuator and the actuator deflection was recorded while the frequency was increased from $0 \mathrm{~Hz}$ to $5000 \mathrm{~Hz}$. The displacement of the actuator was measured with the fiber optic displacement sensor. Figure 11 gives an example of the dynamic response of the actuators. The first and second natural frequencies were observed at $17 \mathrm{~Hz}$ and $110 \mathrm{~Hz}$. The deflection was observed to plateau between the first and second natural frequency and not decline sharply as with many other types of actuators. In addition this plateau occurred at a larger deflection than observed prior to the first natural frequency. These results suggest the possibility that the actuators may be effective at frequencies up to the second natural frequency. 


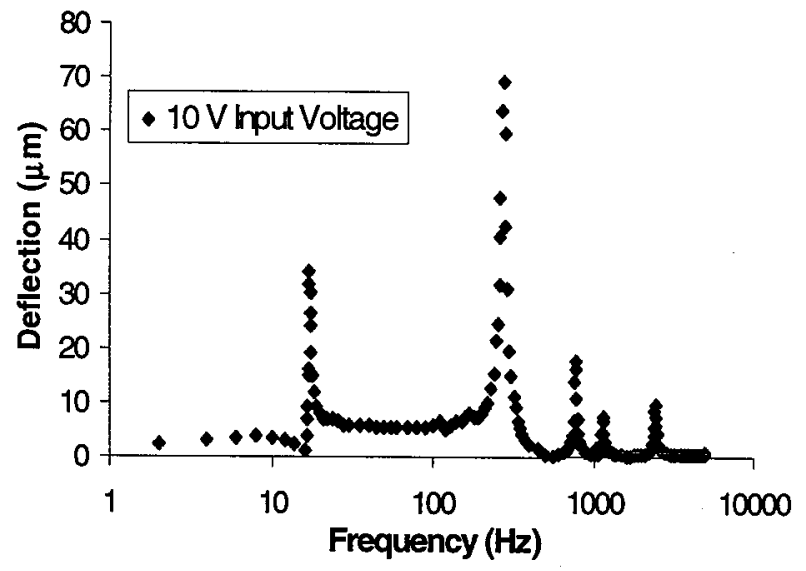

Figure 11: Dynamic Response of C-block Actuator 1: The deflection of actuator 1 in response to an input signal of $10 \mathrm{~V}$ applied over a $5000 \mathrm{~Hz}$ frequency range.

\section{Active Rotor Blade Bench-top Tests}

Once the actuation system was characterized, it was integrated into the wind tunnel test specimen as shown in Figure 7. The performance of the integrated actuator and blade system was evaluated by performing three types of tests. First, the blade's angular deflection was tested statically, at $0 \mathrm{~Hz}$. These results were compared to the results from the static tests on the actuators alone, and used to determine the losses incurred by the integration of the actuators with the flap. Second, the system was tested quasi-statically, at $1 \mathrm{~Hz}$, to eliminate any creep or stiction that may be encountered in the static tests. Third, the system was tested dynamically from $1 \mathrm{~Hz}$ to $40 \mathrm{~Hz}$ to determine the deflection performance at the target frequency of $28 \mathrm{~Hz}$ and across the entire bandwidth.

\section{Experimental Apparatus}

Experimentation on the rotor blade-actuator system was conducted with the experimental setup pictured in Figure 12. The blade was secured to the table to prevent erroneous results arising from movement of the entire structure. Sinusoidal input waveforms were produced by an HP 33120A function generator with amplification accomplished by a Trek 50/750 amplifier connected directly to the C-block actuators. Angular deflections were measured by reflecting a laser beam off of a mirror located on the flap, onto a calibrated scale mounted on the ceiling.

\section{Static tests}

Although the intended use of the system is for vibration control and not static usage, the static tests reveal the efficiency of the power transfer through the system. To obtain static measurements, the voltage was increased from $0 \mathrm{VDC}$ to $75 \mathrm{VDC}$ and then decreased to -75

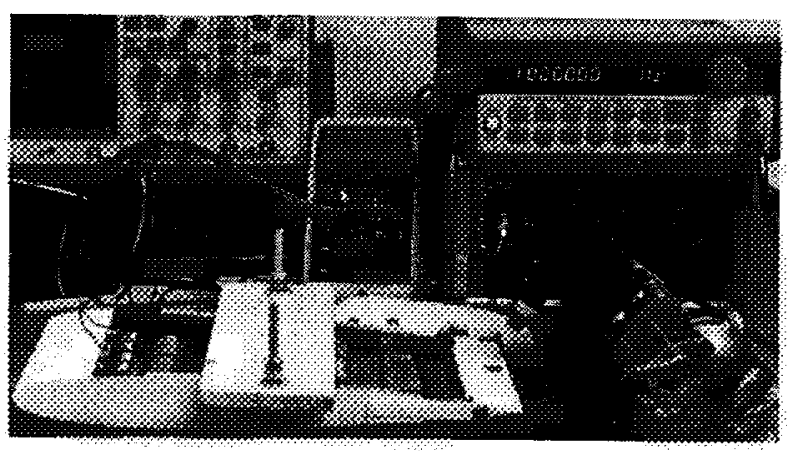

Figure 12: Static Angular Flap Deflection: Angular deflection of the active rotor blade flap as a function of the applied voltage. Three tests were conducted with voltage amplitudes of $75 \mathrm{~V}, 150 \mathrm{~V}$, and $225 \mathrm{~V}$ applied at $0 \mathrm{~Hz}$.

$\mathrm{VDC}$, and returned to $0 \mathrm{VDC}$, in increments of $15 \mathrm{~V}$. This process was repeated two more times, increasing the range tested to $\pm 150 \mathrm{VDC}$ and \pm 225 VDC. The higher maximum voltage was chosen to show a greater range of performance of the wind tunnel test specimen without undue risk to the actuators.

The results of the static performance along with the theoretical model are shown in Figure 13. The theoretical model was determined by calculating the expected average linear deflection of the two actuators (equation 1) and using the geometry of the system to predict the angular flap deflection. Peak-to-peak deflections of $2.3^{\circ}$ at $75 \mathrm{~V}, 5.6^{\circ}$ at $150 \mathrm{~V}$, and $9.6^{\circ}$ at $225 \mathrm{~V}$.

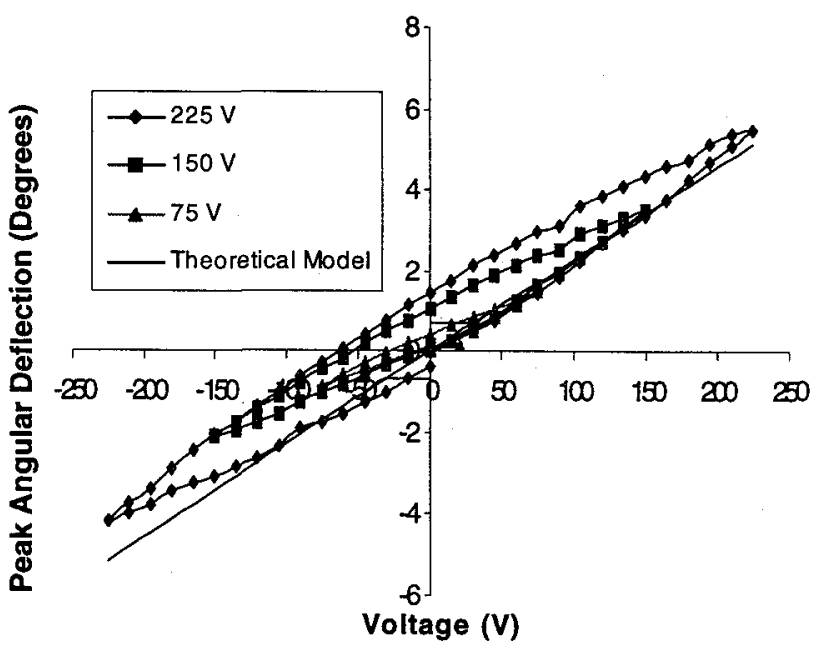

Figure 13: Static Angular Flap Deflection: Angular deflection of the active rotor blade flap as a function of the applied voltage. Three tests were conducted with voltage amplitudes of $75 \mathrm{~V}, 150 \mathrm{~V}$, and $225 \mathrm{~V}$ applied at $0 \mathrm{~Hz}$. 
The experimental data tracked the theoretical model very well during the initial application of voltage. As the voltage is lowered from the maximum voltage for each test, $75 \mathrm{~V}, 150 \mathrm{~V}$, and $225 \mathrm{~V}$, the effect of hysteresis becomes prevalent and causes the vertical deviation in the experimental data above the theoretical line. Hysteresis effects were not included in the theoretical model and hence the hysteresis accounts for the majority of the error in the prediction of flap deflections.

The analytical model overpredicted the experimentally determined total peak to peak angular deflection by $9.1 \%$ at $225 \mathrm{~V}$ demonstrating the power loss incurred by the integration of the actuators with the flap system. The power loss is primarily attributable to friction in the flap pivot bearings and a small amount of interference that was noted between the flap and the skin of the blade section. If the data is extrapolated to include the maximum allowable voltage of approximately $340 \mathrm{~V}$, peak-to-peak deflections of over $14^{\circ}$ are expected.

\section{Quasi-static tests}

To eliminate the possible effects of creep incurred with DC excitation, quasi-static system tests were conducted. To obtain quasi-static measurements, the voltage was increased from $0 \mathrm{~V}$ to $75 \mathrm{~V}$, then decreased to $-75 \mathrm{~V}$, and returned to $0 \mathrm{~V}$, in increments of $15 \mathrm{~V}$. This process was repeated two more times, increasing the range tested to $\pm 150 \mathrm{VDC}$ and $\pm 225 \mathrm{VDC}$. The frequency of the applied voltage was held constant at 1 $\mathrm{Hz}$ for all quasi-static experimentation.

The results of the quasi-static tests are shown in Figure 14. Peak-to-peak deflections of $2.1^{\circ}, 4.8^{\circ}$, and $8.4^{\circ}$ were obtained for input voltages of $75 \mathrm{~V}, 150 \mathrm{~V}$ and $225 \mathrm{~V}$ respectively. As discussed in Hall and Prechtl, the static measurements are higher due to creep effects, which were eliminated by the $1 \mathrm{~Hz}$ input signal used in the quasi-static tests. As a result of the creep, the static measurements overstate the system's performance capabilities. The percentage increase in deflection was negligible for small voltages with less than a $1 \%$ increase at $75 \mathrm{~V}$. However, the increase in deflection was significant for the $150 \mathrm{~V}$ and $225 \mathrm{~V}$ tests where $17 \%$ and $14 \%$ increases were measured, respectively. The increase in deflection of the static results over the quasi-static results could not be attributed completely to creep in the actuators as experimentation on the actuators alone revealed a maximum creep of under $6 \%$ at $225 \mathrm{~V}$. Friction is likely the cause for the remaining loss in deflection in the quasi-static tests. The sinusoidal input voltage applied during quasi-static

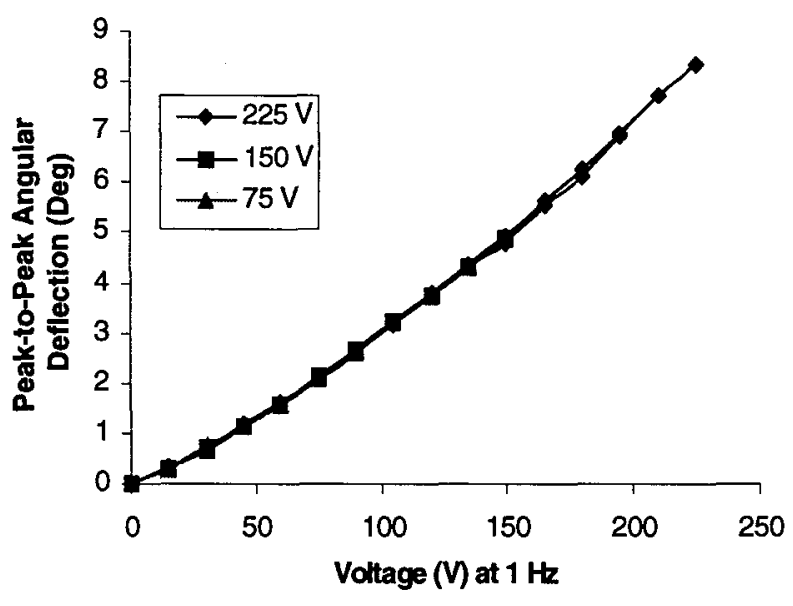

Figure 14: Quasi-static Angular Flap Deflection: Peak-to peak angular deflection of the active rotor blade flap as a function of voltage applied at $1 \mathrm{~Hz}$. Three separate tests were conducted: In the first test the voltage was varied from $-75 \mathrm{~V}$ to $75 \mathrm{~V}$, in the second test from $-150 \mathrm{~V}$ to $150 \mathrm{~V}$, and in the third test from $-225 \mathrm{~V}$ to $225 \mathrm{~V}$.

experimentation causes the flap to slow as it approaches the point of maximum deflection and therefore may not have sufficient energy to drive through much friction at the peak of the actuation stroke. In contrast, the input voltage during static experimentation is applied abruptly in $15 \mathrm{~V}$ increments which may impart sufficient energy to the flap to drive through more friction than in the quasi-static experimentation.

\section{Dynamic tests}

The dynamic performance of the active rotor blade test article was experimentally found to determine the systems natural frequencies and if the system was capable of producing large flap deflections over a substantial frequency range. Dynamic angular flap measurements were obtained by exciting the actuators at three different voltages $75 \mathrm{~V}, 150 \mathrm{~V}$ and $225 \mathrm{~V}$. The input signal was swept from $1 \mathrm{~Hz}$ to $40 \mathrm{~Hz}$ in increments of $1 \mathrm{~Hz}$. The pre-load applied to the Cblock actuators, adjusted by tightening the lock nuts in Figure 7, can have a significant effect on the frequency response function of the system. An increase of the preload places the piezoceramic into compression and alters the stiffness of the actuators. The effect of the pre-load applied to the actuators on the dynamic characteristics of the system was investigated by performing the dynamic experiments with high and low pre-load settings. 


\section{High Pre-load}

A high pre-load was applied to the actuators by tightening the lock nuts in Figure 7. The peak-to-peak angular deflections for the high pre-load setting were recorded at each frequency and are shown in Figure 14a. The high pre-load setting resulted with a first natural frequency occurring at approximately $27.5 \mathrm{~Hz}$. At the target frequency of $28 \mathrm{~Hz}$, flap deflections of 2.8 ${ }^{\circ} \mathrm{pp}$ were obtained for an input voltage of $75 \mathrm{~V}, 6.6^{\circ} \mathrm{pp}$ for $150 \mathrm{~V}$, and $10.3{ }^{\circ} \mathrm{pp}$ for $225 \mathrm{~V}$. Throughout the entire frequency range tested, the deflection never dropped below $8.3^{\circ} \mathrm{pp}$, and peaked at $11.6^{\circ} \mathrm{pp}$ at 40 $\mathrm{Hz}$ for an applied voltage of $225 \mathrm{~V}$.

The spike in the deflection at the natural frequency of $27 \mathrm{~Hz}$ is not only reduced by damping in the system, but also by the method of attachment between the actuator and the flap. In order to cause deflections of the flap, extension/contraction of the actuators in the chord-wise direction is necessary. However, the first natural frequency acts like the first bending mode of a cantilevered beam. This mode results in motion that is approximately perpendicular to the chord-wise direction for small angles, which is especially true for the smaller input voltages. Even as the voltage is increased to 225 $\mathrm{V}$, the interference between the blade structure and the actuators limits the angular motion of the actuators, thereby limiting the chord-wise motion of the actuators. As a result the increase in flap deflection at resonance is minimized.

A problem that was noted is that the first mode of the actuators occurred at approximately $27 \mathrm{~Hz}$, which is

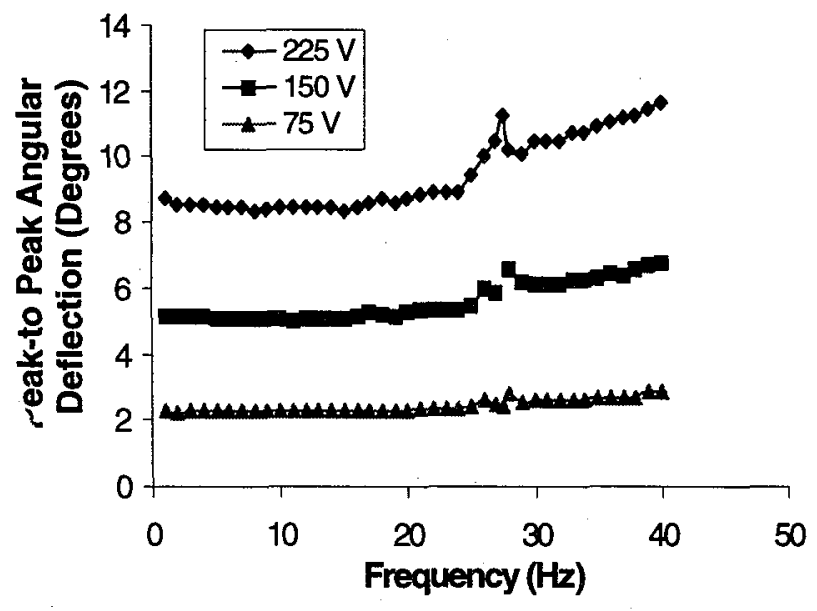

a) High Pre-load Dynamic Response close to the target operational frequency of $28 \mathrm{~Hz}$. The target frequency is based on the necessary frequency of flap oscillation needed to control the $\mathrm{N} / \mathrm{rev}$ vibrations for a typical helicopter, with $\mathrm{N}$ equal to the number of blades. In this work, a typical helicopter with 4 blades and a blade speed of 420 RPM $(7 \mathrm{~Hz})$ was chosen as the target recipient for the flap system.

Operation at the natural frequency will significantly reduce the life of the actuators. However, the natural frequency can be readily altered by adjusting the preload on the actuators; therefore the first mode can located anywhere between approximately $22 \mathrm{~Hz}$ and 32 $\mathrm{Hz}$. This allows the first mode to be shifted above or below the target frequency, reducing stress on the system during operation.

\section{Low Pre-load}

The pre-load on the actuators was reduced by loosening the lock nuts in Figure 7 to determine the effect of the pre-load on the flap deflection. The low pre-load setting resulted in a different frequency response function as seen in Figure 14b. The location of the first natural frequency is difficult to determine because there is not a distinct resonant peak. The onset of the rise in deflection occurs at $22 \mathrm{~Hz}$ where an angular flap deflection of $8{ }^{\circ} \mathrm{pp}$ was obtained at $225 \mathrm{~V}$. At the target frequency of $28 \mathrm{~Hz}$, flap deflections of $2.6^{\circ} \mathrm{pp}$ were obtained for an input voltage of $75 \mathrm{~V}, 6.2^{\circ} \mathrm{pp}$ for 150 $\mathrm{V}$, and $10.9^{\circ} \mathrm{pp}$ for $225 \mathrm{~V}$. At $28 \mathrm{~Hz}$ the flap deflections for the low pre-load test are nominally the same as those for the high pre-load test even though 28 $\mathrm{Hz}$ is no longer a natural frequency in the load pre-load

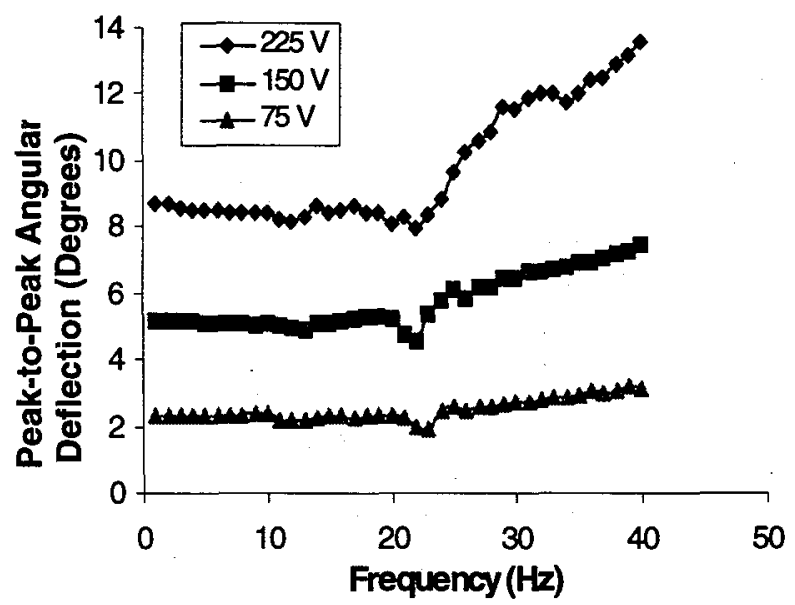

b) Low Pre-load Dynamic Response

Figure 15: Dynamic Angular Flap Deflection: Peak-to-peak angular flap deflection of the active rotor blade flap in response to an input voltage of $75 \mathrm{~V}, 150 \mathrm{~V}$, and $225 \mathrm{~V}$ applied at $0 \mathrm{~Hz}-40 \mathrm{~Hz}$. a) High pre-load applied to both actuators. b) Low pre-load applied to both actuators. 
setting. Throughout the entire frequency range tested, the deflection never dropped below $8^{\circ} \mathrm{pp}$, and peaked at $13.6^{\circ} \mathrm{pp}$ at $40 \mathrm{~Hz}$ for an applied voltage of $225 \mathrm{~V}$.

The overall peak-to-peak values for the high versus low pre-load settings are close, however the overall functional response differs slightly. The different frequency response function seen with the lower preload setting occurs for primarily for two reasons. First, the natural frequency is lowered because of the reduced tension in the actuators. This however does not explain the different shape of the response function. One possible explanation is the changing of the end conditions on the actuators. As the tension is reduced in the actuators, the point of attachment between the actuators and the cap screws becomes less like a clamped end condition and more like a pinned end condition. As the end condition goes through this transition, the first mode, cantilevered bending, will be reduced in magnitude, becoming non-existent in the limiting case of a perfectly pinned beam. The second mode of the cantilevered beam shifts downward in frequency and increases in magnitude as the end condition becomes more like a pinned end condition. In the case of this experiment, the end condition is somewhere between perfectly pinned and perfectly clamped. It was observed that at the attachment point of the actuators, a visibly larger degree of rotation occurred for the low pre-load case than the high preload case, providing support for this explanation.

\section{Conclusion}

This paper presents the design and bench-top validation of an active rotor blade flap system driven by C-block serial actuators designed to reduce the vibrations of a helicopter rotor blade. From this characterization, the following can be concluded:

- Static experimentation on the actuators resulted with maximum deflections of $92 \mu \mathrm{m}$ for actuator 1 and $101 \mu \mathrm{m}$ for actuator 2 , in response to a 150 VDC input signal. The deflection-voltage model was capable of predicting this response with an average error of $4.8 \%$ and $4.9 \%$ for actuators 1 and 2 respectively.

- Maximum blocking forces of $10.1 \mathrm{~N}$ for actuator 1 and $9.2 \mathrm{~N}$ for actuator 2 were measured in response to a $150 \mathrm{VDC}$ signal. The force-deflection model was capable of predicting this response with an average error of $2.6 \%$ for each actuator.

- The variation in the stiffness between the actuators is attributable to the $40 \%$ difference between the thickness of each actuators epoxy bonding layer which affixes the piezoceramic to the steel substrate.

- Quasi-static experimentation on the integrated blade-actuator system produced angular flap deflections of $8.4^{\circ} \mathrm{pp}$ obtained with a $225 \mathrm{~V}, 1 \mathrm{~Hz}$ input signal. The quasi-static flap deflections were lower than the static flap deflections of $9.6^{\circ} \mathrm{pp}$ also obtained at $225 \mathrm{~V}$. The larger static angular deflections are attributed to effects of creep and friction.

- The location of the first natural frequency of the integrated blade-actuator was observed to be highly dependent on the pre-load applied to the actuators. Adjustment of the pre-load was observed to shift the location of the first natural frequency between $22 \mathrm{~Hz}$ and $32 \mathrm{~Hz}$.

- Maximum flap deflections of $11.6^{\circ} \mathrm{pp}$ for the high pre-load setting and $13.6^{\circ} \mathrm{pp}$ for the low pre-load setting were observed at the maximum frequency tested of $40 \mathrm{~Hz}$.

- The deflection of the C-block actuators was observed to plateau between the first and second natural frequencies at a larger magnitude than achieved before the first natural frequency. As a result, the system was capable of being driven over a large frequency range, $0 \mathrm{~Hz}-40 \mathrm{~Hz}$, while producing flap deflections greater than $8^{\circ} \mathrm{pp}$ (at $225 \mathrm{~V}$ ) over the entire range.

- If the voltage is increased to the maximum allowable voltage of $340 \mathrm{~V}$, the attainable flap deflection could reach a maximum of $20^{\circ} \mathrm{pp}$ and produce $12^{\circ} \mathrm{pp}$ over the entire $40 \mathrm{~Hz}$ frequency range, thus exceeding the design goal of $10^{\circ} \mathrm{pp}$.

The promising results demonstrated during this benchtop testing, coupled with the balanced construction of the rotor blade flap, demonstrate that C-blocks have potential as an alternative actuation scheme for active rotor blade flap systems.

\section{References}

${ }^{1}$ F. K. Straub and D. J. Merkley 1997, "Design of a smart material actuator for rotor control," Smart Materials and Structures, 6:26-34.

${ }^{2}$ V. Giurgiutiu, C. A. Rogers, and R. Rusovici 1996, "Solid-State Actuation of Rotor Blade Servo-flap for Active Control," Journal of Intelligent Material Systems and Structures, 7:192-202. 
${ }^{3}$ R. Rusovici and H. H. Cudney 1997, "Design and Testing of a Helicopter Trailing Edge Flap with Piezoeletric Stack Actuators," in Smart Structures and Materials 1997: Smart Structures and Integrated Systems, M. Regelbrugge, Ed. SPIE Vol. 3041: 146157.

${ }^{4}$ E. F. Prechtl and S. R. Hall 1997, "Design of a High Efficiency Discrete Servo-Flap Actuator for Helicopter Rotor Control," in Smart Structures and Materials 1997: Smart Structures and Integrated Systems, M. Regelbrugge, Ed. SPIE Vol. 3041: 158-182.

${ }^{5}$ T. Spencer and I. Chopra 1996, "Design and Testing of a Helicopter Trailing Edge Flap with Piezoeletric Stack Actuators," in Smart Structures and Materials 1996: Smart Structures and Integrated Systems, I. Chopra, Ed. SPIE Vol. 2717: 120-131.

${ }^{6}$ N. A. Koratkar and I. Chopra 1997, "Testing and Validation of a Froude scaled Helicopter Rotor model with Piezo-Bimorph actuated Trailing Edge Flaps," in Smart Structures and Materials 1997: Smart Structures and Integrated Systems, M. Regelbrugge, Ed. SPIE Vol. 3041: 183-205.

${ }^{7}$ S. R. Hall and E. F. Prechtl 1996, "Development of a piezoelectric servoflap for helicopter rotor control," Smart Materials and Structures, 5:26-34.

${ }^{8} \mathrm{M}$. V. Fulton and R. A. Ormiston 1997, "Hover Testing of a Small-Scale Rotor with On-Blade Elevons,"'Proc. AHS 53rd Annual Forum, Virginia Beach, Virginia, April 29-May 1.

${ }^{9}$ A. J. Moskalik and D. Brei 1998, "Quasi-Static Behavior of Individual C-Block Piezoelectric Actuators," accepted for publication in the Journal of Intelligent Material Systems and Structures.

${ }^{10} \mathrm{D}$. Brei 1993, "The Development of a Polymeric Piezoelectric Bimorph Microactuator-Based

Macroactuator for an Artificial Hand," PhD Thesis: Arizona State University

${ }^{11}$ A. Moskalik and D. Brei, "Theoretical and Experimental Investigations of the Deflection Response of Series Configurations of Piezoelectric C-Block Actuators," submitted to the Journal of Intelligent Material Systems and Structures.

${ }^{12}$ A. Moskalik and D. Brei 1998, "Force-deflection Characterization of Series Arrays of Piezoelectric Cblock Actuators," presented at the SPIE $5^{\text {th }}$ Annual International Symposium on Smart Structures and Materials, San Diego CA, March 1998. 